\title{
Perancangan Sistem Informasi Monitoring Sales Karyawan Pada PT. Panen Lestari Indonesia (SOGO PVJ)
}

\author{
Syarif Hidayatulloh $^{1}$, Adi Kusmana ${ }^{2}$ \\ Program Studi Teknik Informatika \\ Fakultas Teknologi Informasi, Universitas Adhirajasa Reswara Sanjaya

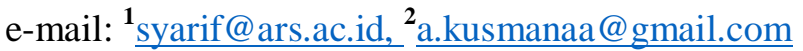

\begin{abstract}
ABSTRAK
Monitoring atau pengawasan dapat diartikan sebagai usaha menentukan apa yang sedang dilaksanakan dengan cara menilai hasil/prestasi yang dicapai dan jika terdapat penyimpangan dari standar yang telah ditentukan, maka segera diadakan usaha perbaikan, sehingga semua hasil/prestasi yang dicapai sesuai dengan rencana Pada umumnya monitoring dilakukan oleh para leader atau atasan terhadap bawahan. Pada PT. Panen Lestari Indonesia(SOGO PVJ) pengawasan yang dilakukan oleh leader atau dalam hal ini supervisor belum berjalan optimal karena belum adanya perangkat yang digunakan untuk membantu mengawasi penjualan dari setiap pramuniaga dan pramuniaga perlu untuk mengecek kembali penjualan yang telah terjadi dikasir untuk menyingkronkan dengan data yang pramuniaga punya. Penelitian ini bertujuan untuk membantu supervisor untuk dapat mengawasi penjualan dari setiap pramuniaga yang bertugas dan membantu pramuniaga untuk bisa mengecek/menyingkronkan kembali penjualan yang sudah terjadi di kasir menjadi lebih cepat dan tepat. Dalam pengembangan sistem informasi ini menggunakan metode prototype, hasil dari penelitian ini yaitu perancangan sistem informasi monitoring sales karyawan berbasis web.
\end{abstract}

Kata Kunci : Sistem Informasi, monitoring, metode prototype

\section{ABSTRACT}

Monitoring or supervision can be interpreted as an attempt to determine what is being done by assessing the results / accomplishments achieved and if there are deviations from the standards set, then immediately held repair business, so all results / accomplishments achieved in accordance with the plan In general monitoring is carried by leaders or superiors to subordinates. At PT. Panen Lestari Indonesia (SOGO PVJ) the supervision carried out by the leader or in this case the supervisor has not run optimally because there is no device used to help supervise the sales of each sales assistant and the sales assistant

http://ejournal.urindo.ac.id/index.php/TI 
need to double check the sales that have occurred in the cashier to synchronize with the sales clerk have. This study aims to help supervisors to be able to supervise the sales of each salesperson on duty and to help the sales assistant to be able to check / synchronize sales that have occurred at the cashier more quickly and accurately. In developing this information system using the method prototype, the results of this research is the design of information system sales monitoring a-based employee web.

Keywords: Information Systems, monitoring, method prototype

\section{PENDAHULUAN}

Monitoring atau pengawasan dapat diartikan sebagai usaha menentukan apa yang sedang dilaksanakan dengan cara menilai hasil/prestasi yang dicapai dan jika terdapat penyimpangan dari standar yang telah ditentukan, maka segera diadakan usaha perbaikan, sehingga semua hasil/prestasi yang dicapai sesuai dengan rencana (Ramli \& Hardini, 2014).

Proses Pengawasan melalui tahapan-tahapan sebagai berikut

a. Mengukur hasil/prestasi yang dicapai

b. Membandingkan hasil yang dicapai dengan yang diinginkan (standar) dan mencari penyimpangan kalau ada.

c. Memperbaiki penyimpangan

SDM(Sumber Daya Manusia) dalam hal ini disebut pramuniaga. Pramuniaga adalah karyawan dan/atau karyawati yang bekerja pada sebuah perusahaan dagang. Pramuniaga merupakan salah satu jenis profesi, maka Pramuniaga pun dituntut untuk memiliki kinerja yang profesional. Pramuniaga yang kompeten dan profesional sesungguhnya akan bekerja untuk meningkatkan kinerja dirinya. Sehingga hasilnya akan berimbas kepada peningkatan kinerja dan omzet dari perusahaan(Ciptono, 2017).

Dalam penelitian bertajuk The Opportunity of Indonesia yang digagas oleh TEMASEK dan Google, pertumbuhan e-commerce Indonesia meningkat seiring dengan tumbuhnya penggunaan internet di Indonesia. Pada tahun 2015, terdapat 92 http://ejournal.urindo.ac.id/index.php/TI juta pengguna internet di Indonesia. Pada 2020, diprediksi pengguna internet Indonesia akan meningkat menjadi 215 juta pengguna. Dari angka total pengguna internet tersebut, pada 2015, terdapat 18 juta orang pembeli online di Indonesia. Pada tahun 2025 mendatang, 119 juta orang diprediksi menjadi pembeli online di Indonesia. Maka tak heran, peningkatan tersebut akan mengerek nilai pasar ecommerce Indonesia. TEMASEK dan Google memprediksi bahwa nilai pasar ecommerce Indonesia akan mencapai angka $\$ 81$ miliar pada tahun 2025 (Zaenudin, 2017).

Berdasarkan pengamatan langsung pada PT. Panen Lestari Indonesia(Sogo PVJ) pengaruh dari invasi ecommerce ini, tidak terlalu berpengaruh pada penjualan, nyatanya masih banyak pelanggan yang memang senang berbelanja dengan cara konvensional di toko offline karena ada juga kelebihan nya yang salah satunya "Kepercayaan tinggi" yaitu pelanggan bisa langsung melihat dan melihat kualitas dari produk yang di tawarkan bahkan untuk beberapa barang bisa langsung dicoba ditempat yang telah disediakan sehingga produk yang dibeli dijamin memberikan kepuasan secara langsung kepada pelanggan (Desra, 2020).

Kelebihan tersebut harus dimanfaatkan sebaik baiknya oleh PT. Panen Lestari Indonesia(SOGO PVJ). Salah satu caranya yaitu dengan menciptakan pramuniaga yang lebih baik dalam segi penjualan barang sehingga pelanggan yang sengaja data ke toko karena memang lebih senang datang langsung tidak sia-sia tetapi menjadi manfaat untuk penjualan perusahaan, untuk itu diperlukannya pengawasan terhadap kinerja pramuniaga dari segi penjualan. Selain itu mempercepat alur penyampaian data penjualan yang ada di sistem kepada pramuniaga yang nantinya diteruskan kepada perusahaanperusahaan yang telah bekerja sama juga dapat 
dilakukan karena pada sebelumnya pada PT. Panen Lestari Indonesia(SOGO PVJ) penyampaian data penjualan yang dilakukan itu setiap pramuniaga harus menemui admin penjualan untuk dapat melihat dan menyocokan data penjualan yang mereka punya dengan data yang ada di sistem, hal itu meyebabkan antrian dan pemborosan waktu karena banyaknya pramuniaga yang ingin mengecek dan menyocokan penjualan ditambah antrian tersebut berakibat pramuniaga tidak ada di area penjualan untuk melayani pelanggan yang sengaja data ke toko karena memang lebih senang datang langsung. Tidak adanya pramuniaga di area penjualan juga dapat menyebabkan pelanggan tadi akan menjadi kurang bermanfaat karena tidak jadi membeli barang.

Berdasarkan uraian diatas, maka dapat disimpulkan bahwa dibutuhkannya pengawasan terhadap kinerja pramuniaga yang bertugas dalam segi penjualan dan mempercepat proses penyampaian data penjualan kepada pramuniaga supaya pramuniaga tetap ada di area penjualan dan melayani pelanggan yang sengaja datang ke toko. Sehingga untuk mempermudah melakukan pengawasan penjualan dari pramuniaga dan mempermudah pengecekan kembali data penjualan oleh pramuniaga dibutuhkanya rancangan sistem informasi untuk mendukung kegiatan tersebut.

Penelitian mengenai sistem informasi monitoring sudah banyak dilakukan, seperti penelitian yang dilakukan oleh (Ramadhan et al., 2017) dengan judul "Perancangan Sistem Informasi Monitoring Skripsi" di Universitas Gadjah Mada yang mengembangkan cara agar mahasiswa dituntut untuk dapat menyesuaikan, mengatur dan mengendalikan dirinya agar mencapai tujuan yang diinginkan dan juga memfasilitasi perencaan terarah agar proses skripsi lebih teratur.

Adapun penelitian lainya dilakukan (Farihah, 2012) dengan judul "Sistem Informasi Monitoring dan Evaluasi Proses Pembelajaran Berbasis Web pada Fakultas Teknik Universitas Muria Kudus" yang mengembangkan cara untuk menghasilkan suatu sistem informasi berbasis web untuk mempermudah pemantauan proses pembelajaran yang ada pada fakultas teknik di Universitas Muria Kudus. Sistem ini dirancang dengan menggunakan pemodelan UML. Sedangkan bahasa pemrograman yang digunakan adalah PHP dan database MySQL. Hasil http://ejournal.urindo.ac.id/index.php/TI dari rancang bangun ini adalah website "monitoring dan evaluasi (monev) proses pembelajaran" yang mana website ini dititik beratkan pada pengelolaan pemantauan pembelajaran yang selama ini berlangsung pada Fakultas Teknik. Sehingga dapat menjadi dasar untuk penyempurnaan dimasa mendatang.

\section{METODE}

Dalam melakukan suatu penelitian, diperlukannya suatu metode yang menjadi panduan dasar dalam melakukan penelitian. Pada penelitian ini, metode yang di gunakan adalah metode literatur. Metode literatur adalah suatu metode penelitian yang mengumpulkan data dan informasi yang berkaitan dengan penelitian melalui buku, jurnal, internet. Setelah metode literatur dilakukan maka metode selanjutnya adalah membuat ana-lisa perencanaan yang terdiri atas metode pengembangan, pengujian dan analisaakhir. Ketika metode pengembangan aplikasi telah dilakukan maka langkah yangakan dilakukan selanjutnya adalah pengembangan sistem untuk pengujian hingga program aplikasi selesai dikerjakan.

Metode pengembangan aplikasi yang digunakan dalam penelitian ini adalah metode software development life cycle (SDLC). SDLC merupakan pola yang diambil untuk mengembangkan sistem perangkat lunak, yang terdiri dari tahap-tahap rencana(planning), analisis (analysis), desain (design), implementasi (implementation), uji coba (testing) dan pengelolaan (maintenance). Salah satu model dari metode SDLC adalah model prototype.

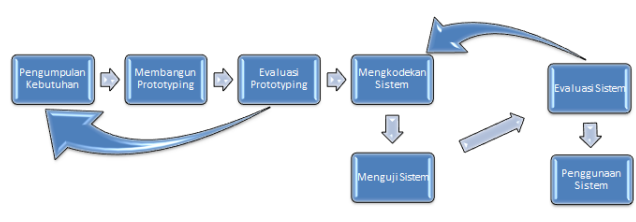

Gambar 1. Prototype 
Adapun tahap tahap dalam menggunakan model prototype ini sebagai berikut

1. Pengumpulan kebutuhan, dimana pengembang dan subyek bersama-sama mendefinisikan format seluruh perangkat lunak, mengidentifikasikan semua kebutuhan, dan garis besar sistem yang akan dibuat

2. Membangun prototyping, dimana pengembang membangun prototyping dengan cara membuat perancangan sementar yang berfokus pada penyajian kepada pelanggan.

3. Evaluasi prototyping, dimana evaluasi ini dilakukan oleh subyek apakah prototyping yang sudah dibangun sesuai dengan kebutuhan. Jika sesuai maka langkah 4 akan diambil, jika tidak sesuai maka prototyping akan di revisi dan mengulang langkah 1, 2, dan 3 .

4. Mengkodean Sistem, dimana dalam tahap ini prototyping yang sudah sesuai akan diterjemahkan ke dalam bahasa pemograman yang ditentukan.

5. Menguji Sistem, dimana setelah sistem sudah menjadi suatu perangkat lunak yang siap pakai, harus di tes dahulu sebelum digunakan. Pengujian ini biasa dilakukan yang biasa di sebut White Box, Black Box, dll.

6. Evaluasi Sistem, dimana subyek akan mengevaluasi apakah sistem yang sudah jadi sesuai dengan yang di harapkan, jika sesuai maka langkah 7 dilakukan tetapi jika tidak sesuai akan mengulangi langkah 4 dan 5 .

7. Menggunakan sistem, dimana perangkat lunak yang telah diuji dan diterima subyek siap untuk digunakan.

Beberapa kelebihan dari model prototype :

1. Subyek ikut dalam pengembangan sistem yang akan memudahkan pengembang mengetahui produk yang diharapkan pelanggan.

2. Analisa kebutuhan lebih mudah diwujudkan.

3. Mempersingkat waktu pengembangan produk perangkat lunak.

4. Komunikasi yang baik antara pengembang dan pelanggan.

5. Pengembang akan lebih mudah dalam menentukan kebutuhan subyek.

http://ejournal.urindo.ac.id/index.php/TI
6. Penerapan menjadi lebih mudah karena subyek mengetahui apa yang diharapkannya.

Adapun kekurangan dari model prototype :

1. Proses yang dilakukan untuk analisis dan perancangan terlalu singkat.

2. Kurang fleksibel jika terjadi perubahan.

3. Walaupun pemakai melihat berbagai perbaikan dari setiap versi prototype, tetapi pemakai mungkin tidak menyadari bahwa versi tersebut dibuat tanpa memperhatikan kualitas dan pemeliharaan jangka panjang.

\section{Teknik Pengumpulan Data}

Dalam penelitian ini penulis mengggunakan tekhnik pengumpulan data penelitian lapangan (Field Research) yaitu mengumpulkan data dengan melakukan survei lapangan yang ada hubungannya dengan masalah yang diteliti. Jenis penelitian ini dilakukan untuk mendapatkan data primer

a. Observasi, yaitu pengumpulan data yang dilakukan dengan cara meninjau atau mengunjungi perusahaan yang bersangkutan secara langsung, untuk mencatat informasi yang berkaitan dengan masalah yang akan diteliti.

b. Wawancara, wawancara dilakukan dengan tanya jawab kepada kepada salah satu Supervisor dari PT. Panen Lestari Indonesia (Sogo PVJ). Hal ini dilakukan untuk menggali, mengumpulkan, menemukan informasi yang dibutuhkan atau yang berhubungan dengan penelitian.

\section{PEMBAHASAN}

Setiap catatan penjualan dari setiap transaksi yang terjadi di PT. Panen Lestari Indonesia tersimpan di dalam server komputer yang hanya bisa diakses oleh beberapa admin dan untuk pramuniaga yang ingin melihat dan mengecek data penjualan mereka harus melalui admin dengan cara datang ke admin dan mencatat penjualan yang ingin di cek secara manual. Hal itu bisa mengakibatkan antrian walaupun sudah 
dijadwalkan menurut kebutuhan sehingga penulis menyarankan untuk pembuatan aplikasi sistem informasi monitoring sales untuk mempermudah penyampain informasi penjualan.

\section{A. Kebutuhan Pengguna}

Dalam aplikasi ini terdapat dua jenis pengguna, yaitu user sebagai pramuniaga dan admin sebagai admin penjualan yang bertugas.

- User, pengguna jenis ini hanya bisa melihat dan mengecek data penjualan dan data ranking, pengguna jenis ini juga bisa mengolah data photo dan password.

- Admin, pengguna jenis ini bisa melihat dan mengecek data penjualan dan data ranking, dan bisa mengolah data diri semua user dan setiap data yang ada di database.

\section{Kebutuhan Sistem}

Setiap pengguna yang ingin menggunakan aplikasi ini harus melakukan login terlebih dahulu dengan menggunakan email/id karyawan dan password. Setiap pengguna yang melakukan login akan diseleksi menurut jenis pengguna. Untuk pengguna jenis user, pengguna hanya bisa melihat data penjualan dan data ranking sesuai cabang, departemen, sub departemen, maupun brand pengguna ditempatkan sehingga setiap penguna yang berbeda akan mendapatkan data yang berbeda sesuai yang hanya diperlukan dan untuk pengguna jenis admin, pengguna di perkenankan melihat data penjualan dan data ranking hanya menurut cabang saja. Semua ini dilakukan untuk tetap menjaga agar privasi data penjualan tetap terjaga keamanan dan kerahasiaan nya.

\section{Rancangan Prototype}

\section{a. Halaman Login}

Pada Halaman Login ini adalah halaman yang mengharuskan pengguna untuk memasukan email atau id dengan password yang telah didapatkan sebelum nya untuk bisa masuk ke dalam sistem. Berikut adalah gambar rancangan prototype halaman login yang telah dibuat.

http://ejournal.urindo.ac.id/index.php/TI

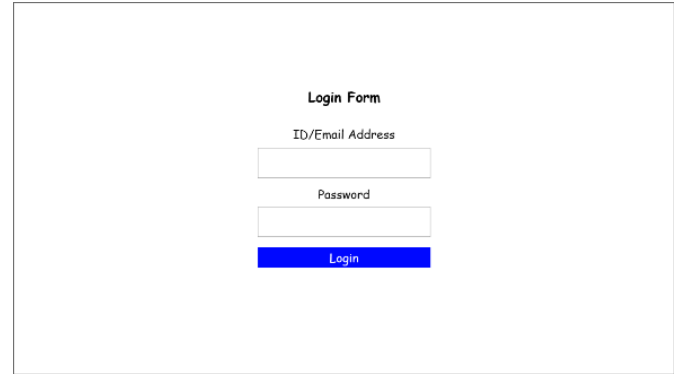

Gambar 2. Prototype Halaman Login

\section{b. Halaman Utama}

Pada Halaman Utama ini adalah halaman dimana halaman pertama yang dihadapi pengguna setelah masuk ke sistem, di halaman ini pengguna bisa memilih menu mana saja yang telah disediakan oleh sistem sesuai keperluan nya masing-masing. Berikut adalah gambar rancangan prototype halaman utama yang telah dibuat.

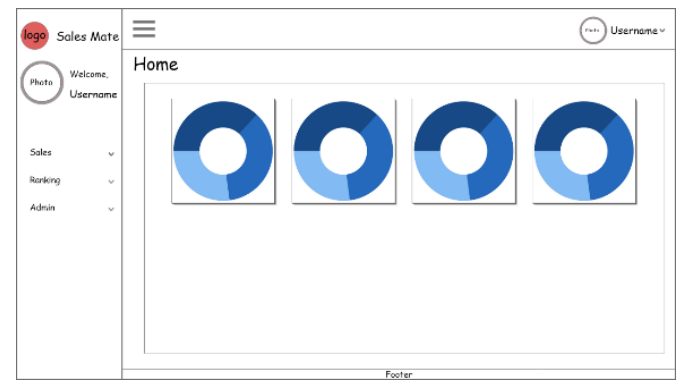

Gambar 3. Prototype Halaman Utama

\section{c. Halaman Data Pengguna}

Pada Halaman Data Pengguna ini adalah halaman dimana pengguna yang telah masuk ke sistem bisa melihat data diri masing-masing dan bisa juga mengubah data yang telah disimpan disistem sesuai ketentuan. Berikut adalah gambar rancangan prototype halaman data pengguna yang telah dibuat.

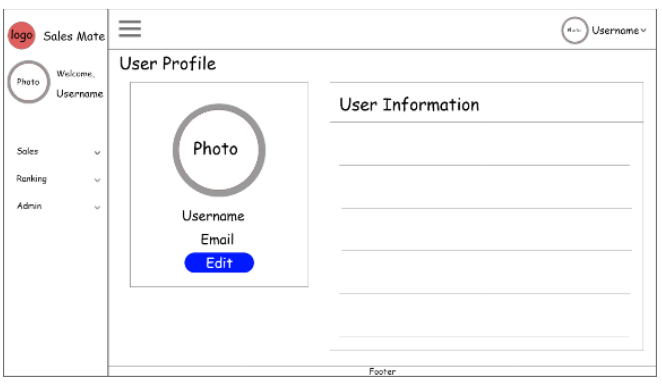


Gambar 4. Prototype Halaman User Profile

\section{f. Halaman Data Ranking}

Pada Halaman Data Ranking ini adalah halaman dimana pengguna yang telah masuk ke sistem bisa melihat data ranking penjualan, data ranking yang bisa dilihat berbeda sesuai ketentuan. Pengguna hanya tinggal mengisi form yang telah disediakan untuk melihat data ranking. Berikut adalah gambar rancangan prototype halaman data ranking yang telah dibuat.

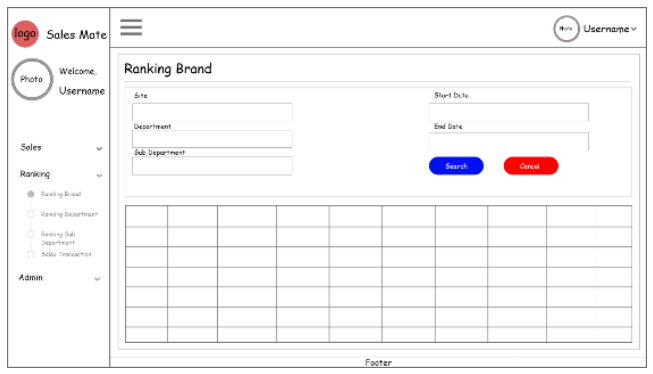

Gambar 7. Prototype Halaman Data Ranking

Gambar 5. Prototype Halaman Pencarian Data Penjualan

\section{e. Halaman Hasil Pencarian Data Penjualan} Pada Halaman Hasil Pencarian Data Penjualan ini adalah halaman dimana pengguna yang telah masuk ke sistem bisa melihat data penjualan yang tersimpan didalam sistem sesuai ketentuan, pengguna bisa melihat data penjualan sesuai dengan hasil pencarian yang telah dilakukan di halaman pencarian data penjualan. Berikut adalah gambar rancangan prototype halaman hasil pencarian data penjualan yang telah dibuat.

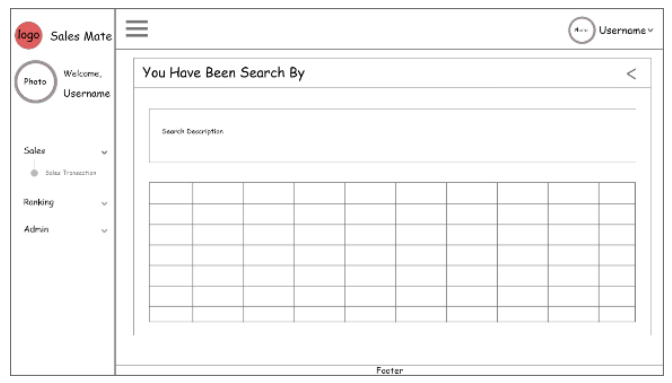

Gambar 6. Prototype Hasil Pencarian Data Penjualan

http://ejournal.urindo.ac.id/index.php/TI 


\section{h. Halaman Tambah Data Pengguna atau Data yang ada di Halaman Admin}

Halaman ini adalah salah satu bagian dari halaman admin yaitu halaman tambah data dimana setiap submenu halaman admin memiliki halaman ini untuk menambahkan data kedalam sistem. Berikut adalah gambar rancangan prototype halaman admin bagian tambah data yang telah dibuat.

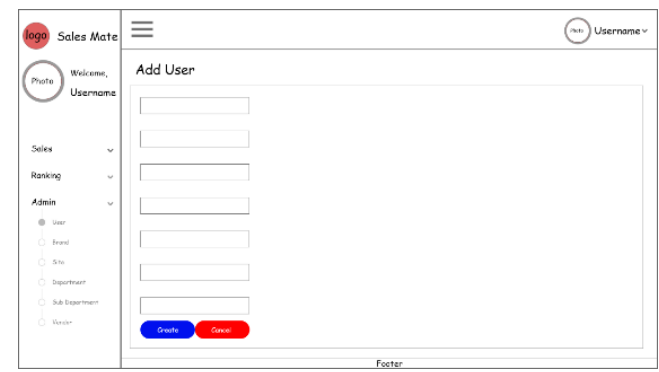

Gambar 9. Prototype Halaman Admin Tambah Data

\section{i. Halaman ubah data pengguna atau data yang ada di halaman admin}

Halaman ini adalah salah satu bagian dari halaman admin yaitu halaman ubah data dimana setiap submenu halaman admin memiliki halaman ini untuk mengubah data didalam sistem. Berikut adalah gambar rancangan prototype halaman admin bagian ubah data yang telah dibuat.

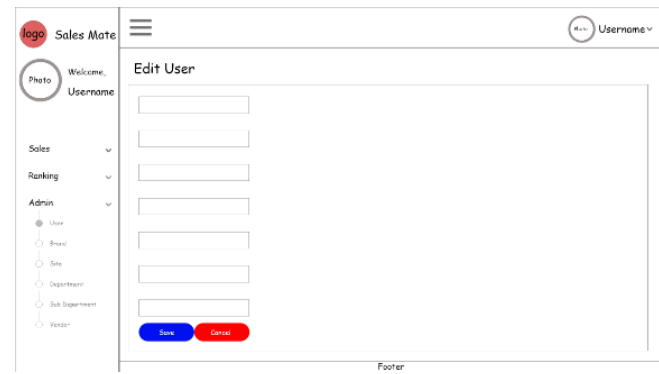

Gambar 10. Prototype Halaman Admin Edit Data

\section{Use Case Diagram}

Pada bagian use case diagram ini menjelaskan mengenai kegiatan atau aktivitas apasaja yang bisa dilakukan oleh pengguna.

a. Use Case User

http://ejournal.urindo.ac.id/index.php/TI
Kegiatan yang bisa diakses oleh pengguna dengan akses user yaitu : kelola data diri, lihat data penjualan dan lihat data ranking. Berikut adalah rancangan use case diagram yang telah dibuat :

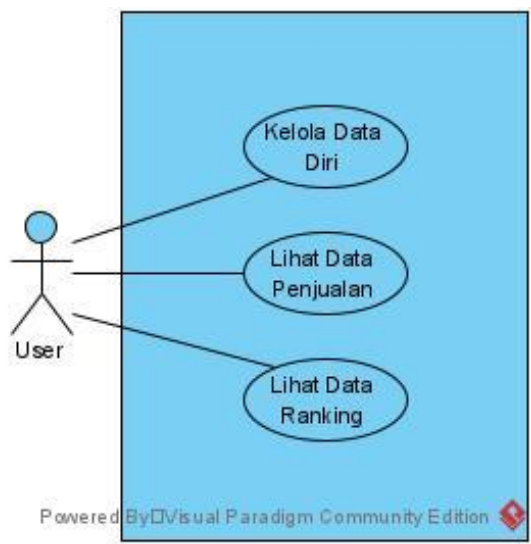

Gambar 11. Use Case User

b. Use Case Admin

Kegiatan yang bisa diakses oleh pengguna dengan akses admin yaitu : kelola data diri, lihat data penjualan dan lihat data ranking, kelola data user, kelola data vendor, kelola data department, kelola data sub department, kelola data brand dan upload transaksi. Berikut adalah rancangan use case diagram yang telah dibuat : 


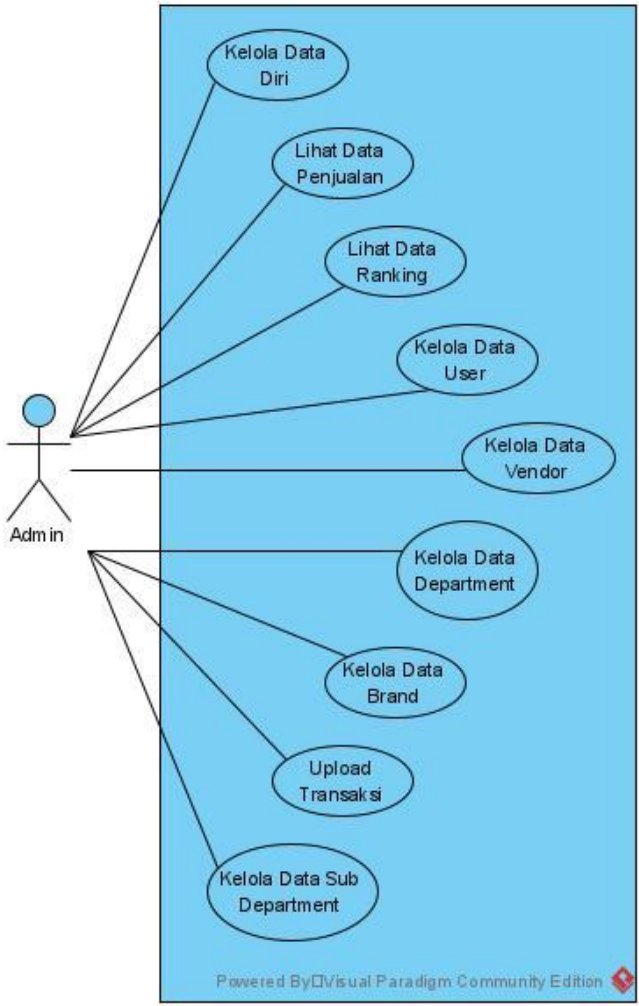

Gambar 12. Use Case Admin

\section{Activity Diagram}

a. Activity Diagram untuk menu Data Sales

Transaction dan Data Ranking

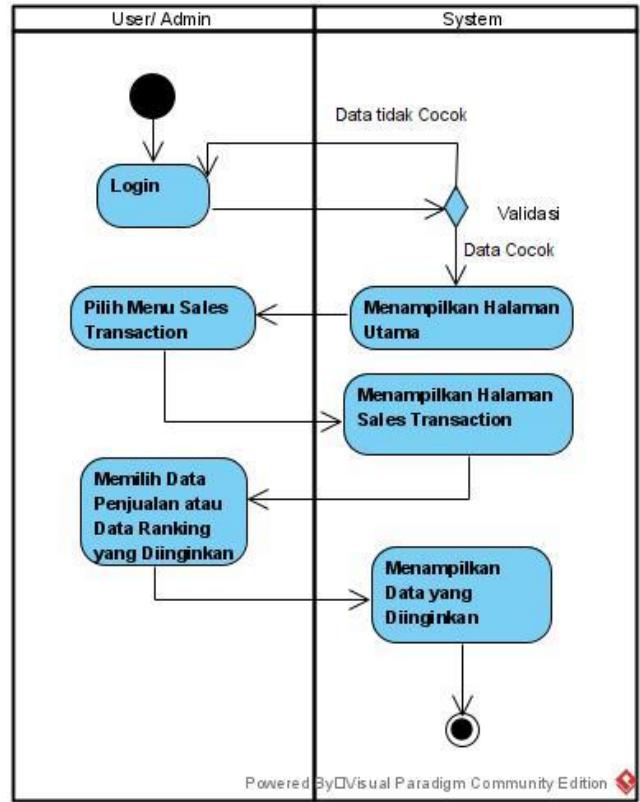

Gambar 13. Activity Diagram Data Sales Transaction

b. Activity Diagram Menu Admin

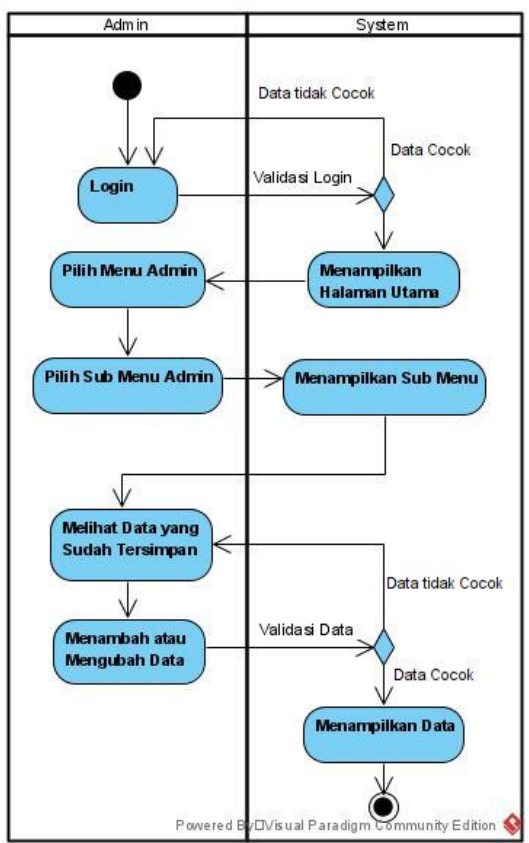

Gambar 14. Activity Diagram Menu Admin 


\section{Tampilan Aplikasi}

\section{a. Halaman Login}

Untuk masuk ke halaman selanjutnya pengguna diharuskan untuk memasukan ID karyawan atau email dan password yang telah di daftarkan oleh admin sebelumnya.

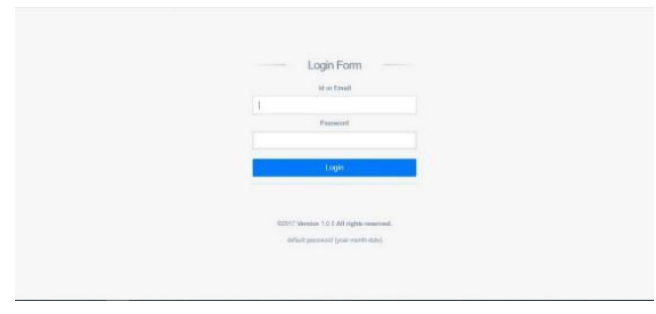

Gambar 15. Halaman Admin

\section{b. Halaman Utama}

Tampilan home pada aplikasi SalesMate sedikit berbeda dari jenis pengguna nya untuk menyesuaikan kebutuhan pengguna itu sendiri, yang membedakan adalah di halaman utama untuk admin ada menu tambahan yaitu "admin". Pada halaman ini menampilkan sedikit data informasi penjualan.
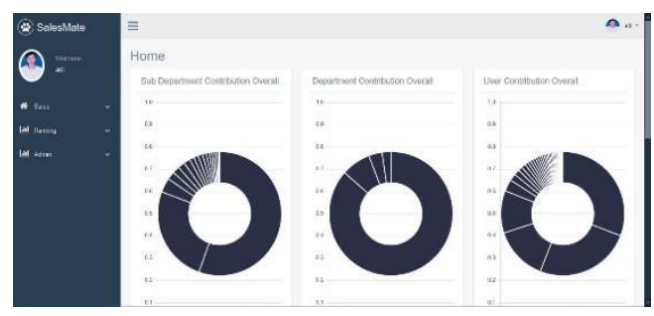

Gambar 16. Halaman Utama Admin

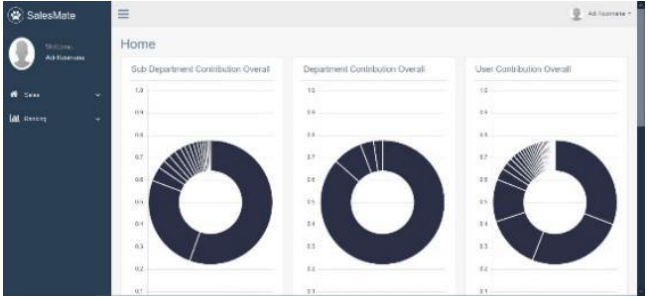

Gambar 17. Halaman Utama User

\section{c. Halaman User Profile}

Menampilkan semua informasi pengguna yang tersimpan pada sistem database, di dalam halaman ini ada dua tombol untuk mengubah data pengguna. Data yang bisa diubah melalui halaman ini hanya photo dan password.

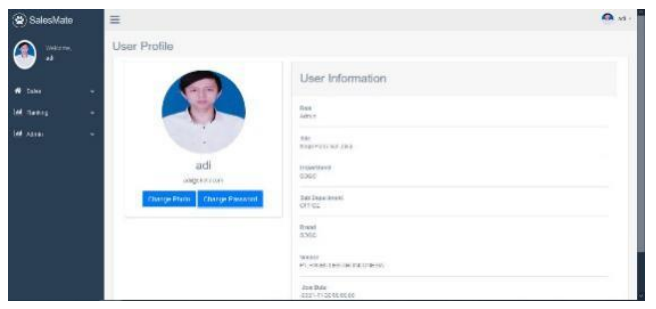

Gambar 18. Halaman User Profile

\section{d. Halaman Sales Transaction}

Halaman ini digunakan untuk melihat dan mengecek penjualan, tampilan untuk halaman ini sama untuk semua jenis pengguna hanya ada beberapa yang dibedakan untuk menyesuaikan kebutuhan.

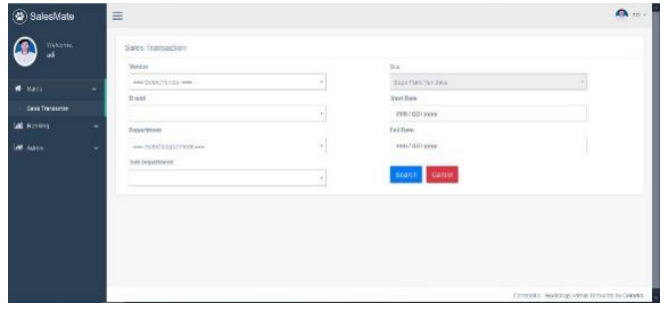

Gambar 19. Halaman Pencarian Data Penjualan 


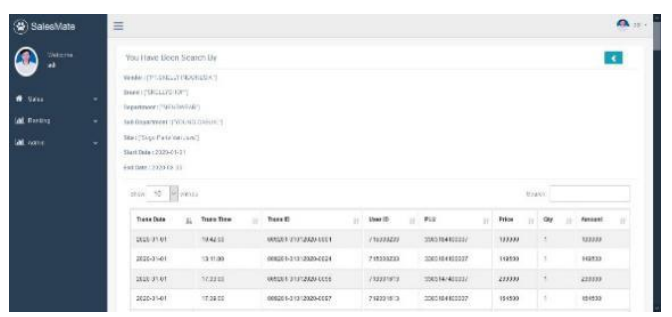

Gambar 20. Halaman Hasil Pencarian Data Penjualan

\section{e. Halaman Ranking}

Pada halaman ranking terdapat beberapa jenis ranking yang bisa dilihat oleh semua pengguna, yaitu ranking berdasarkan cabang, berdasarkan brand, berdasarkan user, berdasarkan departemen, dan berdasarkan sub departemen. Halaman dari setiap kategori tersebut mirip, dan tampilan untuk halaman ini sama untuk semua jenis pengguna hanya ada beberapa yang dibedakan untuk menyesuaikan kebutuhan

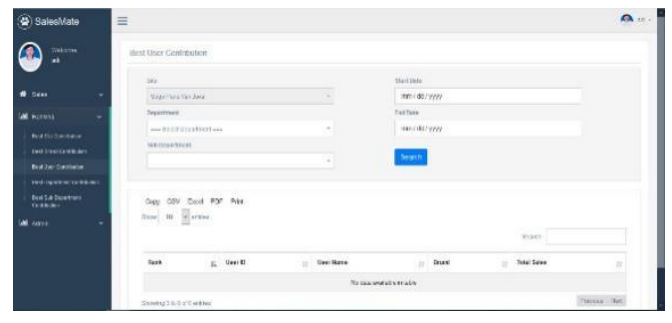

Gambar 21. Halaman Pencarian Data Ranking

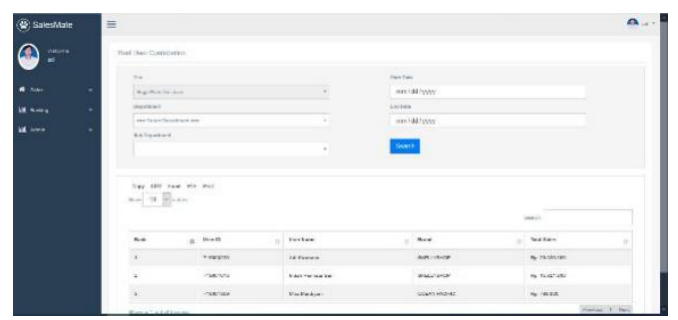

Gambar 22. Halaman Hasil Pencarian Data Ranking

\section{f. Halaman Admin}

Halaman menu admin adalah halaman yang hanya bisa dilihat dan di akses oleh pengguna jenis admin. Halaman menu ini berisi tentang data yang http://ejournal.urindo.ac.id/index.php/TI tersimpan pada sistem database yang diperuntukan khusus untuk admin untuk bisa dikelola demi kelancaran aplikasi ini. Didalam menu admin ini ada beberapa sub menu yaitu user, site, brand, department, sub department, vendor dan upload transaction. Setiap sub menu menu memiliki tampilan yang hampir sama memiliki halaman index dimana halaman ini menampilkan semua data yang tersimpan di database menurut tabelnya masing masing, memiliki halaman create dimana halaman ini diperuntukan untuk menambah data ke dalam sistem database, memiliki halaman edit dimana halaman ini diperuntukan untuk mengubah data yang sudah ada didalam sistem database kecuali sub menu upload transaction itu hanya ada halaman untuk upload nya saja.

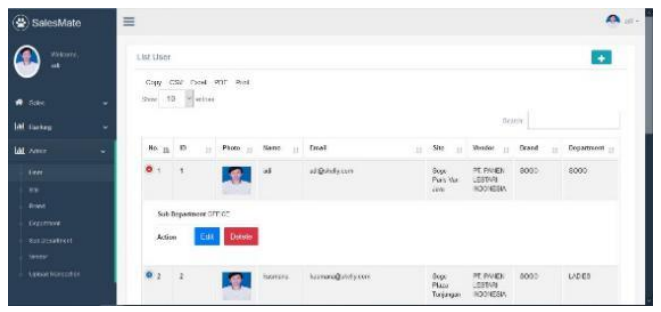

Gambar 23. Contoh Halaman Index pada Halaman Admin

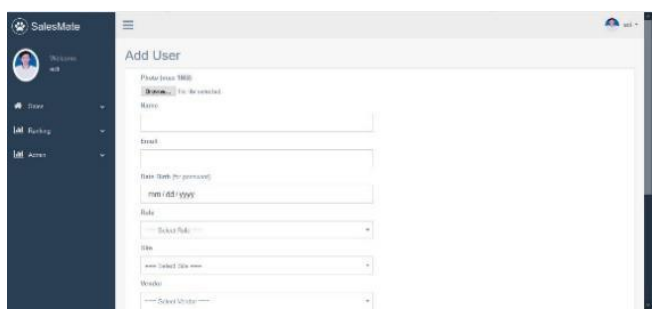

Gambar 24. Contoh Halaman Create pada Halaman Admin

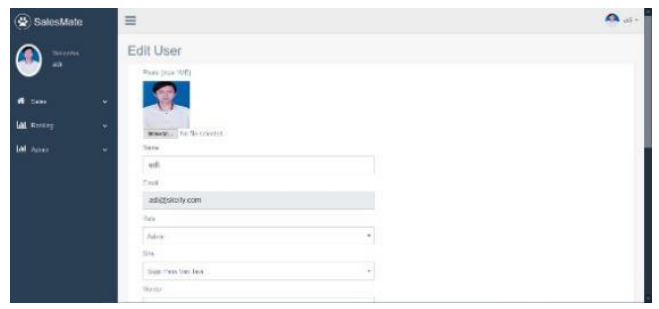

Gambar 25. Contoh Halaman Edit pada Halaman Admin 


\section{g. Halaman Upload Transaksi}

Halaman ini diperuntukan untuk jenis pengguna admin dimana halaman ini digunakan untuk memasukan data penjualan yang sebelumnya belum ada didalam sistem database

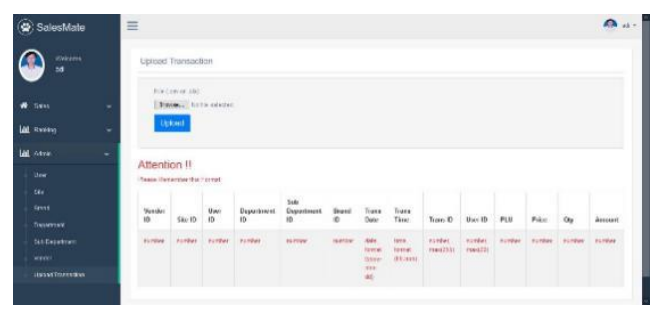

Gambar 26. Halaman Upload Transaksi

\section{SIMPULAN}

Berdasarkan analisa yang telah diuraikan pada bab sebelumnya, penulis menarik kesimpulan sebagai berikut :

1. Perancangan sistem informasi monitoring sales karyawan berbasis web pada PT. Panen Lestari Indonesia(SOGO PVJ) ini dapat mempermudah pihak perusahaan dalam hal ini manager/supervisor untuk melihat data kontribusi dari setiap pramuniaga yang bertugas yang berguna untuk mengevaluasi pramuniaga yang banyak berkontribusi terhadap penjualan dengan yang kurang berkontribusi yang bisa digunakan kedepannya untuk perbandingan.

2. Dengan adanya sistem informasi berbasis web ini yang bisa dilihat dari berbagai platform, dari mulai komputer, laptop, tablet, maupun handphone pramuniaga bisa lebih leluasa mengecek data penjualannya masing masing dimanapun dan kapanpun.

3. Data penjualan yang didapat oleh pramuniaga lebih valid karena yang mengecek data penjualan yang tersimpan pada sistem itu pramuniaga sendiri bukan dari admin yang mungkin saja ada human error.

4. Data penjualan yang tersimpan pada sistem lebih terjaga kerahasiaan nya, karena setiap pramuniaga hanya bisa melihat data penjualan nya masing masing sesuai pada data login yang dipakai.

5. Setelah sistem informasi ini dipakai, otomatis antrian akan hilang karena pramuniaga tidak perlu mengantri untuk dapat mengecek penjualannya. Yang berdampak nantinya area penjualan tidak akan pernah kososng dikarenakan pramuniaga yang sedang mengecek data penjualannya

\section{DAFTAR PUSTAKA}

1. Ciptono, W. P. (2017). Komunikasi Penjualan: Menuju Pramuniaga Juara. Elex Media Komputindo.

2. Desra. (2020). Toko Offline Vs Online: Kelebihan \& Kekurangannya yang Harus Diketahui. https://www.jurnal.id/id/blog/toko-offline-vsonline-kelebihan-kekurangannya/

3. Farihah, U. (2012). Sistem Informasi Monitoring Dan Evaluasi Proses Pembelajaran Berbasis Web Pada Fakultas Teknik Universitas Muria Kudus. Program Studi Sistem Informasi Fakultas Teknik Universitas Muria Kudus Kudus.

4. Ramadhan, M. R., Nugroho, L. E., \& Sulistyo, S. (2017). Perancangan Sistem Informasi Monitoring Skripsi. Proceedings of Conference on Information Technology and Electrical Engineering, 290-295.

5. Ramli, R., \& Hardini, S. Y. P. K. (2014). Asas Asas Manajemen (1st ed.). Universitas Terbuka.

6. Zaenudin, A. (2017). Profil Konsumen Belanja Online di Indonesia. Tirtoid. 